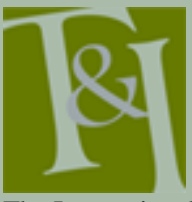

The International Journal for Translation \& Interpreting Research

trans-int.org

\title{
Testing Interpreters: Developing, Administering, and Scoring Court Interpreter Certification Exams
}

\author{
Lois Feuerle \\ LoisMarieFeuerle@cs.com
}

DOI: $10.12807 /$ ti.105201.2013.a04

\begin{abstract}
Access to justice for Limited English Proficient (LEP) and non-English speakers in the U.S. courts is contingent upon the provision of complete and accurate interpreting services. This has been increasingly recognized over the course of the past 35 years or so, and there are currently three major tests administered nationally in the United States to assess interpreting skills in courtroom settings: (1) the Federal Court Interpreter Certification Examination administered on behalf of the United States Administrative Office of the Courts; (2) the examination, widely known as the Consortium Test, administered by 40 or so states, originally developed under the auspices of the National Center for State Courts by the former Consortium for State Court Interpreter Testing, which was recently restructured as the Consortium for Language Access; and (3) the NAJIT Test, developed by the National Association of Judiciary Interpreters and Translators at the request of its membership in order to raise the standards for the profession. In addition, both New York and California, historically states with high levels of immigration, early on developed their own testing procedures to meet statewide needs.

All of these examinations share numerous communalities, but they are also different in a variety of ways. This paper will provide an overview of the three national testing models plus New York, outlining their similarities and differences and pointing out some of the advantages and disadvantages of each model.
\end{abstract}

Keywords: court interpreter; court interpreter testing; court interpreter exams; interpreter testing; federal court interpreter examination; consortium test; National Center for State Courts; NCSC; Consortium for State Court Interpreter Certification; Consortium for Language Access in the Courts; CLAC; National Association of Judiciary Interpreters and Translators; NAJIT test

There has been a need for interpreters since time immemorial. Whenever there has been contact between individuals or groups who spoke mutually unintelligible languages, interpreters have been pressed into service.

Bilinguals, trilinguals, and polyglots, no matter how they had acquired their linguistic skills, whether positive or negative-immigrants embracing a new life in a new country, slaves captured as the spoils of war, offspring of parents with different mother tongues, or linguists fluent by dint of diligent study - how they had gained their language skills was irrelevant if they happened to be there when an interpreter was needed: Voila! They became the interpreter. Think La Malinche or Sacagawea. No one asked how completely either of these women had mastered the languages they spoke or whether they were actually able to render every possible nuance expressed in any of the languages they spoke. No one asked for credentials. As far as those who needed them knew, they seemed to be able to interpret and that was enough.

And so it used to be with the interpreters in the courts of the United States. Whether their interpreting was good, bad or indifferent, it was the luck of the draw. You might get the natural polyglot educated abroad who had a 
good sense of the cultures in which both languages were embedded and who took great pains to reflect every nuance of the words he or she heard spoken, but you also might get the cook or a waiter from the local ethnic restaurant who himself was still struggling to manage the language of his new country.

It took quite some time for the quality of the interpreted message in the courtroom to be perceived as an important issue. Fortunately it has become clear to thoughtful judges, officials, and scholars, if perhaps not yet to the broad general public, that deficient court interpreting is tantamount to a denial of access to justice and can result in serious injustice. Once attention was drawn to the accuracy of the courtroom message, it was natural to focus that concern on the qualifications of the interpreter.

There are reports in abundance of apparently qualified individuals with impressive resumes, advanced degrees and years of experience, who nonetheless proved under scrutiny to be poor or even totally inadequate interpreters. If impressive credentials, graduate degrees, and years in the courtroom are no guarantee that someone possesses the requisite skill set to perform well on the job, what could ensure this?

Many believed the answer to this conundrum lay in a system of professional certification. There have been two major periods of activity for the development of court interpreter certification. First, the 1978 Court Interpreter Act ( 28 USC $\S 1827)^{1}$ set the wheels in motion for the testing and certification of interpreters for the federal courts. Then in the mid-1990s the State Justice Institute, ${ }^{2}$ a federal government foundation established in 1984 to improve the quality of justice in state courts, awarded a grant that set the stage for the creation of the Consortium for State Court Interpreter Certification (recently restructured and renamed the Consortium for Language Access in the Courts, CLAC) within the National Center for State Courts and the former Consortium's subsequent development of court interpreting certification exams in a variety of languages.

As the individual states joined the former Consortium, the state court systems themselves began to place increasing emphasis on the certification, qualification, and quality control of the interpreters used in the state courts. Historically the courts in states with high levels of immigration, such as New York and California, were the first to become interested in evaluating the quality of their interpreters. Because both New York and California already had their own testing programs in place, they were not interested in joining the former Consortium in its early years.

At the same time that the former Consortium was beginning to establish itself in the mid 1990s, the National Association of Judiciary Interpreters and Translators (NAJIT), the professional organization of state and federal court interpreters, perceived the need for a certification outside of the federal certification system, and proceeded to develop its own certification examination.

In short, there are currently at least four recognized court interpreter certification examinations in a variety of languages administered in the United States. This paper will provide a brief overview of those different court interpreter tests, with a focus on the Federal Exam, the tests developed by the former Consortium, the NAJIT Exam, and the New York State Exam. In some ways all of these tests are quite similar, but in other ways they are

\footnotetext{
${ }^{1}$ The full text of the Act is available online from: http://www.gpo.gov/fdsys/pkg/USCODE-2009-title28/html/USCODE-2009-title28partV-chap119-sec1827.htm

${ }^{2}$ Grant SJI-91-12A-B-087
} 
rather different. Accordingly, we will first enumerate their general communalities and differences, and then take a closer look at each of them.

It is not surprising that all of these certification tests ${ }^{3}$ share some essential characteristics since they all aim for the same outcome, i.e., to identify those candidates who possess the skills needed to interpret accurately, completely and appropriately in a courtroom setting.

- In general, each test includes a written component of some kind.

- All test the three modes of interpreting used in the courtroom, i.e., consecutive and simultaneous interpreting and sight translation.

- Each one requires that candidates sign a confidentiality agreement that forbids them to discuss the contents of the exam with anyone.

- Each prohibits the use of dictionaries, reference materials, or any other aids.

- Each of these certification exams is currently administered by means of pre-recorded test material.

- The candidates' performance on each of these tests is recorded electronically.

- The exams are usually rated using a combination of scoring units and a global score.

- All of these certification tests are rated by off-site graders.

- All of these certification programs require rater training.

There are, however, significant differences in terms of administration, scoring, and content. Some of these differences in administration are highlighted by asking the following questions:

- Is the test administered by audio/video recording or by audio alone?

- Is a written test a part of the testing process?

- And if the written is part of the process, at what point is it administered?

- Does the written portion of the exam test proficiency in both languages?

- Is the written test a fully integrated component of the certification exam itself or is it merely a language screen designed to weed out the weakest candidates who do not yet possess the requisite language abilities to justify administering the more expensive oral examination?

- What does the written test actually test?

Other differences relate primarily to the administration of the certification tests. The questions that must be asked here are:

- Are all parts of the exam administered at the same sitting?

- If a candidate fails one section must he or she re-take all sections of the exam or only the section or sections that he or she failed?

- How soon is a candidate permitted to re-test?

\footnotetext{
${ }^{3}$ Note that the programs established to ensure a quality threshold for qualification to work in the courts do not use the same terminology to designate the interpreters who have passed their tests (e.g., "certified," "licensed," "approved"). However, for convenience and to avoid confusion we refer to all of these programs as "certification programs" and the individuals who pass these tests as "certified interpreters."
} 
- How often can a candidate re-test?

- How long do test scores remain valid?

Still other differences relate to how the tests are rated:

- How many raters are used to rate each test?

- Do the raters work independently or do they consult with each other as they rate the tests?

- If they consult each other, are the raters sitting together or are they in different physical locations consulting by telephone or e-mail?

- What is the cut score?

- Are any of the tests given a blind re-rating to check for inter-rater reliability?

- Are the tests psychometrically validated?

\section{A Quick Overview of certification tests in the United States}

\section{The Federal Court Interpreter Exam (FCICE)}

The Court Interpreters Act of 1978, 28 USC $\S 1827$ provided specifically that the Director of the Administrative Office of the United States Courts "certify interpreters based on the results of criterion-referenced performance examinations" (28 USC $\S 1827$ (b)(1)). The exam was designed to test for the knowledge, skills, and abilities (KSAs) necessary to be an effective court interpreter.

The Federal Exam consists of both written and oral components, which are administered in alternate years, the oral in odd-numbered years, the written in even numbered years, resulting in a 2-year testing cycle.

The Federal Written exam comprises 200 items, 100 testing English proficiency and 100 testing Spanish proficiency and candidates are allowed up to three hours and fifteen minutes to complete the test. The exam is a multiple choice examination divided into five sections that test reading comprehension, usage (grammar and idioms), error detection, synonyms, and the ability to select the best translation for an underlined word or phrase. There is no actual writing required. A candidate must pass the five sections in each language section with an aggregate score that equals or exceeds the cut score and must also pass both language sections (a high score in one language cannot compensate for a low score in the other language) with a final equated score of $75 \%$ or higher in order to progress to the oral performance examination. A candidate who fails to do so must re-take the entire written examination the next time it is offered.

The content of the Federal Oral Examination is designed to simulate genuine courtroom situations and processes and is based on actual court transcripts that have been carefully edited to meet psychometric requirements (total length, length of utterances for consecutive, structure, terminology, and selection of scoring units). Designed to mirror the types of tasks the candidate would actually encounter in court assignments, the edited test scripts have been reviewed by judges, attorneys, interpreters, linguists and other cultural experts (FCICE, 2013, p. 36, citing Arjona-Tseng, 1985, p. 185). The Federal Oral exam takes approximately one hour to administer. The source material has been electronically recorded, as are the candidates' responses.

The Federal Oral exam is structured in five sections: a sight translation into Spanish (a police report, witness affidavit, or similar text, 230 words, 5 minutes), a sight translation into English (typically a formal legal document in high register Spanish, 230 words, 5 minutes), a simultaneous 
monologue into Spanish (an opening or closing argument of about 840 words delivered at about 120 words per minute, taking a total of about 7 minutes), an examination of a witness in consecutive interpretation into Spanish and English (875-925 words with an 18 minute time limit, including any time needed to take notes and /or request up to 2 repetitions), and a simultaneous interpretation of a dialogue into Spanish (delivery speed up to 160 words per minute, with an average of $150 \mathrm{wpm}, 5$ minutes).

The cut score for the Federal Oral Exam is $80 \%$. The Oral is graded objectively based on the candidate's rendition of 220 pre-selected key words and phrases plus a subjective global assessment, which on rare occasions can slightly raise or lower the key word score. The "scoring units," which have been incorporated into the exam text according to strict test design principles, represent a variety of linguistic and cognitive features that an interpreter must master in order to perform well in the courtroom.

The nine categories of scoring unit fall into three classes:

\section{- Grammar and usage}

A. Grammar/verbs

B. False cognates/interference/literalism

- General lexical range

C. General vocabulary

D. Legal terms and phrases not common in everyday speech

E. Idioms/sayings/ quotes from literature or history.

- Conservation

F. Register/slang/colloquialisms/profanity

G. Numbers/names/ addresses

H. Modifiers/intensifiers/emphases/interjections

I. Embeddings/position

Another important element in the development of the Federal Exam is the creation of a test-specific scoring guide of both acceptable and unacceptable renderings. Special care is taken not to include any regional or localized vocabulary on the test; terminology must be generally acceptable throughout the Spanish-speaking world and American regionalisms are also avoided.

All Federal Exam raters are federally certified court interpreters who have undergone rater training. Each exam is rated by a team of three raters. If a score is borderline, the test is reviewed by a second team of raters. In addition, in order to monitor inter-rater reliability, a randomly chosen $10 \%$ of all exams are reviewed blind as a matter of course by a second team of raters.

Practice tests for both the Written and the Oral are provided in the candidate's handbook (FCICE, 2013) that can be downloaded free of charge from the Internet or ordered as a hard copy for a fee.

The National Center for State Courts, which currently administers the Federal Court Interpreter Certification Program and which served as the home of the former Consortium and now of CLAC, takes rigorous measures to ensure that each version of the exam is reliable, valid, and similar to previous forms in content, structure, and level of difficulty. Each test item is analyzed statistically to evaluate its effectiveness and to make it possible to equate the alternative forms of each version of the exam.

The Federal Exam for Spanish $\leftrightarrow$ English interpreters was first administered in 1980. Although examinations were also developed in Haitian Creole and Navajo, these exams have not been administered since the 1990s. Plans to develop federal certification exams in other languages such as Russian were abandoned in the 1990s, apparently due to the overwhelming demand for Spanish in the Federal Courts. 


\section{The State Court Interpreter Examinations developed by the Former Consortium}

The need to design a testing mechanism for interpreters in the state courts became increasingly apparent in the early 1990s and the Consortium for State Court Interpreter Certification was founded in 1995 to address this need. The Consortium, a pioneering effort led by founding members New Jersey,

Oregon, Washington and Minnesota, was successful and grew over the years to include some 40 member states. However, as a result of the recent restructuring of the Consortium for State Court Interpreter Certification into the Consortium for Language Access (CLAC), the successor organization is no longer a member association, but now covers all 50 states, US territories, and Washington DC (National Center for State Courts, 2009).

As the former Consortium matured and grew, it developed court interpreter exams in a variety of languages to be used by its member states. However, it became clear that the various member states had different needs, depending upon history, immigration patterns, court structure, and politics. One size did not fit all and the various states made adjustments to reflect local circumstances. Thus some states administer the full Written Exam, a 135item multiple-choice test covering English vocabulary and idioms, legal terminology, court-related terms, and procedures - especially in criminal matters, as well as ethics and professional conduct. Other states may use only part of the Written Exam as a language screen, or in a number of cases do not administer the written exam at all. Some member states, on their own, also commissioned an additional translation component (10 sentences of moderate difficulty to be translated into the non-English language) as a supplement to the Written exam. This additional component serves as a "screen" to determine whether a candidate possesses the requisite basic language skills in the non-English language to make passing the Oral Exam likely. The translation component is generally graded on a pass/fail basis. Although the states that do use the translation component have found it a useful screening tool, neither the Consortium or CLAC have recognized it as such. Often the ethics section of the Written Exam is administered only after candidates have established their language proficiency and participated in an orientation.

When and how often to test is a decision made by each state's court system. The cut score based on scoring units for the Written is $80 \%$, and for the Oral the cut score is $70 \%$ to pass the exam and $80 \%$ to earn the Master level credential in those states that grant Master level status. On extremely rare occasions in the very early days of the Consortium, a non-keyword assessment of "acceptable," "borderline," and "non-acceptable" could be applied to the exam as a whole as a corrective measure, if for example, a candidate has performed well on the scoring units but nonetheless consistently failed to accurately render the larger meaning of the interpreted passage. However, this practice has now been abolished.

Grading protocols, number of graders, and grading logistics may also vary. Some states require that the candidate take and pass all three sections of the oral exam (sight, consecutive, and simultaneous) in one sitting, while others permit a candidate to come back at a later date and re-take only those portions of the exam that the candidate did not pass on the first try. For this reason, the portability of a state credential does vary somewhat depending upon the policies of the state in which the exam was administered and the specific reciprocity rules in place in the various receiving states.

That said, however, many essential aspects of the tests developed by the former Consortium are very similar to the Federal Exam. The major differences between these two tests are that there is only one simultaneous 
section on the Oral exam developed by the former Consortium, and that the amount of time allowed to perform each task is slightly longer and the wordsper-minute delivery rate is the same as for the first simultaneous section of the Federal Court Interpreter Examination.

The tests themselves are constructed along the same lines. The Oral Exam developed by the former Consortium tests all three modes of interpreting (sight translation into non-English language, 225 words, 6 minutes; sight into English, 225 words, 6 minutes; consecutive, 850 to 900 words with utterances of varying lengths, 22 to 27 minutes (depending upon the language tested); simultaneous, 800 to 850 words in length, 120 words per minute, 7 minutes).

Like the Federal Exam, the exam developed by the Consortium and still used by the states is recorded, as is the candidate's performance. Raters are generally federally certified in the case of Spanish and must undergo rater training prior to grading test tapes. Unlike the Federal Exam, however, two raters rather than three are generally required; however, a third rater may be consulted in the event of a disagreement or if the objective test score falls into the borderline category.

Unlike the Federal Exam, which currently only tests Spanish, the exams offered by the former Consortium and now by CLAC, are available in a variety of different languages and multiple test forms, and it is left up to each state to decide which languages it wishes to test based on its own statewide needs. Currently the CLAC offers full tests in 18 languages (Arabic, Cantonese, French, Haitian Creole, Hmong, Ilocano, Khmer, Korean, Laotian, Mandarin, Polish, Portuguese, Punjabi, Russian, Somali, Spanish, Tagalog, Vietnamese) plus abbreviated tests in 5 other languages (Bosnian-Croatian-Serbian, Chukkese, Marshallese, Turkish, German). Tests in Eastern Armenian and Farsi are still in development, with their release pending final review.

\section{National Judiciary Interpreter and Translator Certification (NJITCE)} The NJITCE, better known as the NAJIT Exam, is different in that it was developed at the behest and under the sponsorship of a professional organization rather than a governmental agency. The decision to develop a very demanding exam that tests both interpreting and translation skills for court interpreters was made in 1998 based on a survey of the NAJIT's membership.

NAJIT worked in close collaboration with a test development company, with NAJIT providing the substantive content and insight into the KSAs required by court interpreters and the outside company providing the psychometric expertise. It was an expensive enterprise even though NAJIT provided the consultants and subject matter experts free of charge.

The NAJIT Exam was piloted in 2001 and is currently available only in Spanish although there were plans to add other languages in the future. There are 3 forms of the test, which has been administered every year at NAJIT's annual conference as well as at additional times depending upon demand. Eleven states ${ }^{4}$ currently accept successful completion of the NAJIT exam as sufficient qualification for state court certification without further testing.

\footnotetext{
${ }^{4}$ The NAJIT Exam is currently accepted by Colorado, Connecticut, Delaware, Hawaii, Iowa, Massachusetts, New York, Pennsylvania, Rhode Island, Texas, and Wisconsin. It is reported that several other states are working on accepting it in the future.
} 
The NAJIT Exam differs from the Federal and former Consortium examinations in that (1) its Written test includes a demanding translation component to qualify successful candidates to translate as well as to interpret, and (2) the Oral tests the candidate's skill in interpreting both from Spanish into English and from English into Spanish. The NAJIT Written tests the candidate's linguistic abilities in both Spanish and English.

The NAJIT Written Exam is very comprehensive and includes sections on reading comprehension, grammar and syntax, antonyms, synonyms, analogies, idioms, proverbs, ethics, and translation into both English and Spanish. Both the Spanish and English sections of the NAJIT Written are designed to match the level of difficulty of the Graduate Record Examinations (the GREs). Table 1 breaks the test down into sections and lists the number of items in each section.

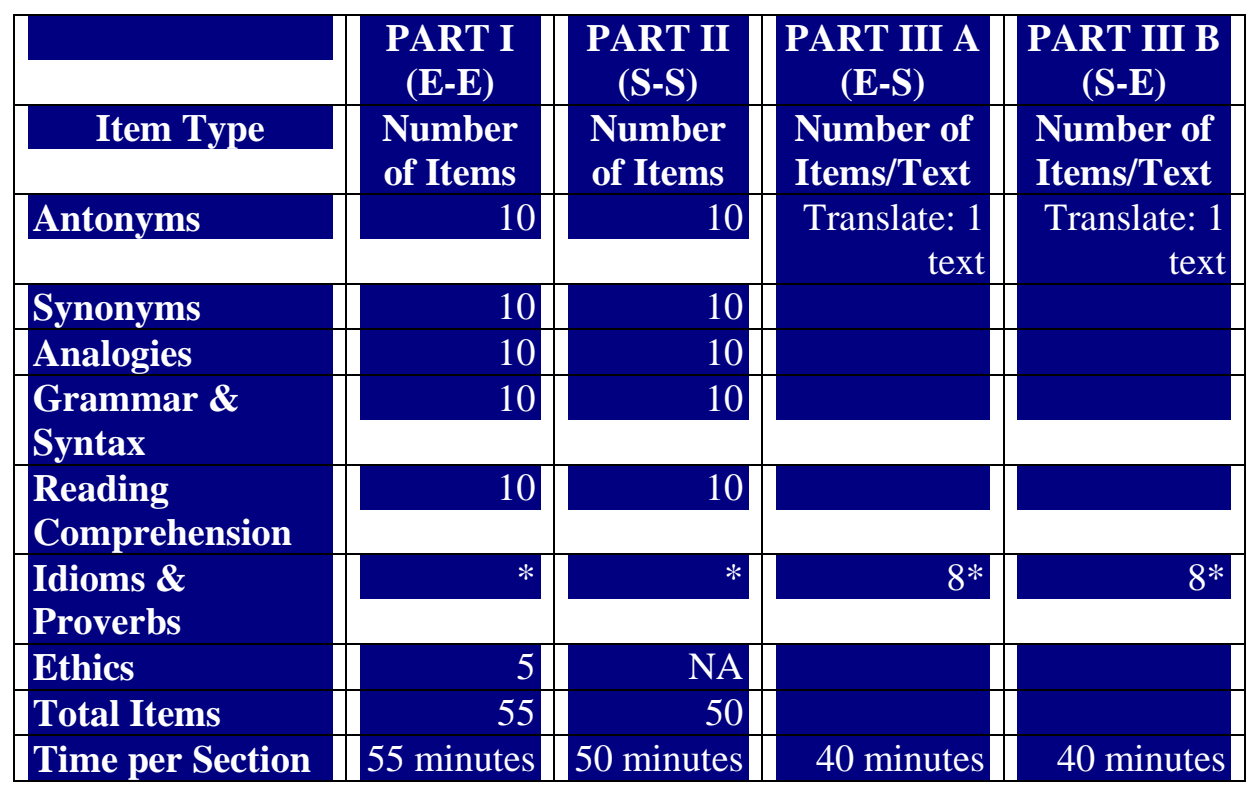

Table 1. Structure of the NAJIT Written Exam and number of items per section. ${ }^{5}$

The NAJIT Oral Exam tests all three modes, with sight translations into both English and Spanish (in each case 250 words, 5 minutes), consecutive (into and out of both languages, 15 to 20 minutes) and 2 simultaneous sections, one going into Spanish and one going into English (total 8 minutes).

\section{New York State Interpreter Testing}

New York City has long been a major gateway for new immigrants to the United States and historically has had a high proportion of residents who did not speak English or who did not speak it well. Currently almost $30 \%$ of New Yorkers, i.e., almost 5 million people, primarily speak a language other than English in the home (New York Unified Court System, 2006, p.1; see also Ferrara \& Gadiraju, 2008) and approximately two and a half million people in New York State do not speak English as their primary language and have limited ability to read, speak, write or understand English (New York Governor's Press Office, 2011). New York State includes not only one of the nation's largest urban centers, but it also has a very large court system with a huge need for qualified court interpreters. In New York City alone there are

\footnotetext{
${ }^{5}$ For a more complete description see the NAJIT website at http://www.najit.org/certification/NJITCE.php
} 
20 separate trial courts: a Civil Court, Criminal Court, Supreme Court, and Family Court for each of the City's five boroughs. Thus it is not surprising that New York State moved to more formal methods of qualifying court interpreters relatively early on.

It should be noted that interpreter testing in New York is subject to somewhat different constraints than in most other states because its staff interpreters (i.e., its court-employed interpreters, as opposed to its voucherpaid per diem freelancers) are largely subject to statutory civil service requirements and public employee union collective bargaining. This means that Spanish staff interpreters ${ }^{6}$ are civil service employees who have passed a competitive civil service exam and have been hired from the top of the ranked eligible list of successful candidates. Successful candidates have the option of being placed on the State Registry for freelance assignments until they are hired as staff.

Although they undergo a process that parallels the certification processes used by the federal courts, the former Consortium and NAJIT, the candidates who successfully complete the New York State Office of Court Administration process are not referred to as "certified."

New York conducted its first Competitive Examination for Spanish in 1980 (New York Unified Court System, 2006, p. 7). A new Competitive Examination for Spanish is developed and administered every four years, but even sooner if it appears that the list of prospective candidates will not be sufficient to meet court system hiring needs. Old examinations are retired completely to eliminate the danger of overexposure of the test instrument.

Like the Federal, former Consortium, and NAJIT Exams, the New York Competitive Examination for Spanish consists of both written and oral components. The New York Written Examination consists of a 3-hour multiple-choice examination of 120 multiple-choice questions evenly weighted between English and Spanish. It is broken down into four components: (1) English/Spanish grammar and usage, (2) vocabulary, (3) reading, understanding and handling written material and (4) translating written material.

The English/Spanish grammar and usage section tests a candidate's ability to apply basic grammar and sentence structure rules in both languages, and the vocabulary section tests general vocabulary (synonyms, antonyms, idiomatic expressions). Specialized legal terminology is not included in the New York Written, the philosophy being that it is most critical to test for the candidate's broad mastery of the two languages in question and the unique subset of skills needed to interpret rather than the narrow specialized vocabulary used in court, but which can be taught relatively easily.

Each paragraph in the reading comprehension portion of the New York Written is followed by a series of related questions. All the information required to answer the questions correctly is provided within the passage itself; no background knowledge is needed to provide the correct answers to the questions. The sentence-completion cloze exercises present the candidate

\footnotetext{
${ }^{6}$ Since 2006 New York has screened interpreters in 22 high-volume languages: Albanian, Arabic, Bengali, BCS (Bosnian, Croatian, Serbian), Cantonese, French, Greek, Haitian Creole, Hebrew, Hindi, Italian, Japanese, Korean, Mandarin, Polish, Portuguese, Punjabi (Eastern), Russian, Spanish, Urdu, Vietnamese, and Wolof. These tests are structured much like the Competitive Spanish Exam - the multiplechoice English examination and an oral exam, but without a non-English written component. Administration is also by video format. Testing in languages other than Spanish is non-competitive, i.e., the successful candidates are not ranked. See Ferrara and Gadiraju (2009, pp. 4-5).
} 
with short written passages containing a number of blanks. Candidates must then choose from a list of alternatives the words that best fit the meaning of both the sentence and the entire paragraph.

The New York Written also tests the ability to translate from English to Spanish and from Spanish to English. Here the candidates are presented with a sentence in English or Spanish and must then choose from subtly different alternatives in the target language the one that best reflects the original meaning and nuance of the source text.

Admission to the New York Oral Performance Assessment is contingent upon passing the Written. As noted, the New York Oral Performance Examination is structurally similar to the Federal, NAJIT and former Consortium exams in that it tests the three modes of interpreting using simulated courtroom documents and situations. Typically the documents chosen as sight translation texts are affidavits, court orders, probation reports, and the like in both Spanish and English. The script for the consecutive is an attorney's examination of a witness. There are three simultaneous sections, a monologue from English into Spanish, a monologue from Spanish into English and a two-voice colloquy between a judge and an attorney from English into Spanish. The judge-attorney exchange includes more specialized vocabulary than in other sections of the test, but expressly avoids highly unusual or technical terminology.

Like the Federal, former Consortium and NAJIT exams, the New York Oral Exam takes approximately one hour for the sight translation and the video presentation of the consecutive and simultaneous portions, and the candidate's performance is recorded on audio. All raters are federally certified and trained (or re-trained) prior to each grading engagement. The exam itself is constructed with carefully selected scoring units embedded in the test scripts, which are taken from actual court transcripts and then edited and revised to meet psychometric requirements. The objective score obtained from the scoring unit count is fine-tuned with a qualitative global assessment of plus or minus 10 points using criteria from a five-point descriptive benchmarked scale that is then added to the total number of correct scoring units to yield the final score. To ensure inter-rater reliability $20 \%$ of all tests are re-graded blind by different raters.

However, the New York Oral differs from the Federal, former Consortium, and NAJIT exams in three significant ways:

1. All sections of the Oral (except for the two sight translation passages) are administered by video rather than by audio recording alone. This means that the candidate has the opportunity to observe the speaker and pick up on all visual clues that would be available in an actual courtroom situation.

2. Like the NAJIT (but unlike the Federal and former Consortium exams), the New York Oral tests not only the ability to interpret simultaneously into Spanish, but it also includes a simultaneous component going into English, often sentencing speeches (either a victim impact statement or a defendant's description of some mitigating circumstances).

3. The consecutive section of the New York Oral video includes pretimed intervals allowing for the candidate's responses so that no proctor intervention is required in administering this portion of the test. While this does eliminate the opportunity for the candidate to request the two repetitions that are built into the other tests described above, it also means that each test is administered in an absolutely identical manner. Most importantly it completely eliminates the 
possibility of certain types of proctor-candidate communication problem, e.g., situations in which a candidate completes or apparently completes his or her rendering of an utterance and only then thinks of a better rendition and then backtracks to self-correct, but only after a pause long enough for the proctor to already have pressed the button to play the next utterance, which then cuts into the middle of the candidate's self-correction. This can be very disconcerting to the candidate as well as to the proctor. The fixed pre-timed intervals can also provide valuable guidance to the testtaker, since if a candidate runs out of time on the first few responses, it becomes clear to the candidate early on that it will be necessary to pick up the pace if he or she does not wish to run out of time on each utterance.

Historically the Spanish interpreter examination has been developed in-house using staff subject matter experts, i.e., seasoned interpreters holding a wide range of credentials that include federal certification, law degrees, Ph.D.s (in languages, linguistics, and other fields), Masters Degrees and paralegal certificates. Some have earned parallel degrees in the same discipline from institutions in the US and in the Spanish-speaking world. The test development process is guided by the psychometricians of the Exam Development and Staffing Research Group.

Because New York has its own in-house psychometricians, it is able to examine test items statistically to assess validity, reliability, predictive value, and equivalence of test forms. A total of 1236 candidates took the Written Exam in 2006, 40\% of whom passed and were eligible to take the Oral Performance Exam. Of the 455 candidates who proceeded to the Oral, only $27 \%$ passed. Only $9.4 \%$ of the candidates who began the process were eligible for employment. This pass rate was similar to that for the exams administered prior to 2006. According to the 2009 technical report by the Exam Development Group, the Written Exam for Spanish demonstrated a high degree of internal consistency and test reliability and a high degree of predictive value for the probability of passing the Oral Exam (Ferrara \& Gadiraju 2009, p. 7 ff.).

This review of the Federal, former Consortium, and NAJIT certification exams and the New York Civil Service Examination for Spanish Interpreters reveals a great many similarities in their essential structure, but also some clear differences. There are also differences in the perception of the relative difficulty of the four tests under discussion here, though if the pass rates on each of these tests are any indication, they are all very challenging. Moreover, even with some differences in content and cut scores, all of these tests have been professionally developed and represent very respectable efforts to try to remove, as much as possible, the barriers that hinder access to justice for those who are limited English proficient or who do not speak English at all.

Any interpreter contemplating seeking certification needs to ask a whole array of questions:

- What languages are tested in the jurisdiction in question?

- How often are these tests offered?

- How far is it necessary to travel to take the desired exam?

- What does each exam cost?

- If it is an exam administered by a state, can out-of-staters take that state's test? 
- If so, how much more will it cost for an out-of-state candidate to take the exam?

- And since a high percentage of test-takers are unsuccessful, is it an all-or-nothing exam or can the candidate put any partial success "in the bank?"

- How long is the entire testing process, and how much time will the quest for certification take?

- And, of course, what about the relative difficulty of each exam?

Few interpreters will opt for a more difficult exam unless there are serious compensating reasons to do so. And this leads to the question, where can the candidate reasonably hope and expect to work? Moreover, the rate of pay differs from jurisdiction to jurisdiction, and the volume of work often depends upon local needs, the number of interpreters available locally and the language pairs one works in.

And finally:

- How can a candidate prepare for the exam?

- What practical experience is needed or advisable?

- How can a candidate get experience if he or she cannot work without certification?

A difficult and potentially vexing calculus indeed.

The answers to some of these questions are simple to ascertain. The federal courts are currently testing only Spanish. If a candidate wants to earn federal certification, it will take at least a year and a half to complete the process from start to finish since the federal courts offer the written and the oral only in alternate years. Thus if a candidate does fail the federal written the first time around, it will take even longer. If a candidate wishes to take a court interpreter test in Wolof, it will be necessary to take the New York test. And even though there is a state court interpreter exam for Ilocano, the candidate's state of residence may choose not to test Ilocano if there is no local need for it. The price structure for testing differs from state to state, depending on where a candidate lives and whether the candidate is in-state or out-of-state. Even if a candidate has failed the simultaneous interpreting section of the state exam, the passing scores obtained on sight translation might be carried forward in the state of current residence, but might be worth nothing in another state where a spouse may be looking for a job.

Similar issues arise when interpreters relocate. For example, will the NAJIT Exam be accepted in the new state? For interpreters, there is much to investigate before making certification decisions, but, in most cases, Internet research will be able to provide the needed information or at least the contact information for someone who is in a position to answer these questions.

What has been the result of these certification efforts to date? The leading exams discussed here are all difficult, the fees are considerable and the pass rates low, so despite the ongoing need for high-quality interpreting, there continues to be a great need for certified interpreters in the US. Many, if not most, of the court interpreters in languages other than Spanish do not hold certification, but often because there is no exam in that language rather than because they were unable to pass the relevant exam. In fact, in the case of many smaller language groups, it is rather unlikely that there will be certification tests developed at any time in the foreseeable future.

Although many decry the fact that scarce resources have been expended to create a multiplicity of exams in Spanish while other languages are neglected, under current conditions it is hard to imagine that it will be 
possible to narrow down the field to only one certification test in the very near future. Will it be possible for an interpreter to use Spanish state certification resulting from passing a Consortium or CLAC test to get his or her name on the ranked eligible list for civil service employment in the State of New York? It seems very unlikely. Will the federal courts accept NAJIT certification (reputed by some to be even more challenging than the Federal Exam) in lieu of federal certification and then pay federal rates to the interpreter in question? Probably not. Will Oregon, which requires that candidates pass the entire certification exam at one administration, accept a certification when the interpreter passed the exam section by section over a five-year period in another state? Not under current rules.

The issues before the courts are crucial to someone-whether a case involves a capital murder or the loss of a driver's license, a multi-million dollar patent or the return of a $\$ 500$ security deposit, but the quality of justice can only be as good as the court processes and procedures that have been developed and implemented. A great deal of what the courts do has farreaching effects on the lives of many, many people, sometimes even life and death. A critical component of what goes on in court is the transfer of information from one language into another so that everyone in the courtroom is hearing the same evidence, the same argument, and the same colloquy. This ideal is a goal worth striving for, even if perfection is elusive and unobtainable. The task may seem Sisyphean, but it is not. Bit by bit the quality of the nation's court interpreters is getting better; inch-by-inch, the boulder is being pushed a little farther up that steep hill. The growth of American certification programs and of their successful implementation is due to the hard work of many dedicated people - interpreters, administrators, scientists, legislators, lawyers, educators, test developers and numerous others - people who are dedicated to attempting to perfect the imperfectible, to the end that we might actually have justice for all. 


\section{References}

Arjona-Tseng, E. (1985). The Court Interpreters Certification Test Design. In Elías-Olivares, L., et al. (Eds.), Spanish Language Use and Public Life in the United States, pp. 181-200. Berlin: Mouton.

FCICE [Federal Court Interpreter Certification Examination]. (2013). Federal court interpreter certification examination handbook, revised edition (January 23, 2013). Williamsburg, Virginia: Federal Court Interpreter Certification Examination. Accessed February 9, 2013 from

http://www.ncsc.org/sitecore/content/microsites/fcice/home/Aboutthe-

program/ /media/Microsites/Files/FCICE/Final\%20Examinee\%20Ha ndbook\%201-23-2013\%20for\%20online.ashx.

Ferrara, P., \& Gadiraju, S. (2008). Assessment issues in identifying languageskilled interpreters for the New York court system. In presentation at the Mid-Atlantic Personnel Assessment Consortium Fall Conference, Baltimore, MD.

Ferrara, P., \& Gadiraju, S. (2009). Language assessment testing for court interpreters in the New York State Unified Court System: Test design, test validation, and psychometric characteristics. Technical report of the Examination Development Group, New York State Unified Court System.

National Center for State Courts. (2009). Court interpreting consortium member states. Retrieved from http://www.ncsconline.org/d_research/CourtInterp/Res_CtInte_Cons ortMemberStatesPubNove07.pdf.

New York Governor's Press Office. (2011, October 6). Governor Cuomo issues executive order to improve access to state services for nonEnglish speakers. Retrieved from http://www.governor.ny.gov/press/10062011nonenglisheo.

New York Unified Court System. (2006). Court interpreting in New York: A plan of action. Retrieved from http://www.nycourts.gov/courtinterpreter/pdfs/action_plan_040506.p df. 